\title{
Rehabilitation for cognitive impairments after cerebral malaria in African children: strategies and limitations
}

\author{
Paul Bangirana', Richard Idro', Chandy C. John ${ }^{3}$ and Michael J. Boivin ${ }^{4,5}$ \\ 1 Department of Mental Health and Community Psychology, Makerere University Institute of Psychology, Kampala, Uganda \\ 2 Department of Paediatrics and Child Health, Mulago Hospital/Makerere University Medical School, Kampala, Uganda \\ 3 Global Pediatrics Program and Division of Pediatric Infectious Diseases, University of Minnesota, Minneapolis, MN, USA \\ 4 International Neurology and Psychiatry Epidemiology Program (INPEP), Michigan State University, East Lansing, MI, USA \\ 5 Neuropsychology Program, Department of Psychiatry, University of Michigan, Ann Arbor, MI, USA
}

Summary

\begin{abstract}
Cerebral malaria results in short- to long-term cognitive impairments in many of its child survivors. Although some of the risk factors for impairments have been identified, no attempts have been made to address the plight of those who develop cognitive impairments. This paper discusses the burden of cognitive impairment caused by cerebral malaria and suggests some rehabilitation strategies based on brain injury and cognitive rehabilitation studies. Potential cognitive rehabilitation solutions such as cognitive exercises, environmental enrichment, nutritional supplementation, physical therapy and speech therapy are highlighted. The limitations of implementing these interventions and solutions are discussed in light of the limited human resources and infrastructure of the developing countries that are malaria endemic.
\end{abstract}

keywords Cerebral malaria, cognitive impairment, Africa, children, rehabilitation

\section{Introduction}

Malaria is a leading cause of ill health in tropical countries. About 515 million clinical episodes were estimated to have occurred in 2002; $70 \%$ in Africa and $25 \%$ in South East Asia and was responsible for about one million deaths in children under 5 years of age in sub-Saharan Africa (Snow et al. 2005). Most of the malaria-related deaths result from the severe forms of falciparum malaria. Cerebral malaria (CM) is the most severe neurological complication of falciparum malaria. Despite adequate medical care, mortality stands at $18.6 \%$ and $10.9 \%$ of survivors are discharged with gross neurological deficits (Newton et al. 2000). Because of this high mortality, little attention has been paid to the long-term outcomes of the disease. However, recent studies have shown that neurologic and cognitive deficits may persist in many survivors of CM. This paper examines the cognitive deficits that follow recovery from $\mathrm{CM}$ and outlines strategies that may help in rehabilitation. A meta-analysis on studies looking at the cognitive impairments in CM was not possible because only a handful of studies using very different methods have been published to date.

\section{Cognitive impairments following cerebral malaria in African children}

The neuropsychological effects of CM were first comprehensively assessed in Ghana, where 20 hospital-referred children who met the World Health Organization (WHO) criteria for CM were compared with 20 healthy children on a battery of neuropsychological tests (Dugbartey 1995; Dugbartey et al. 1998). The CM group displayed significant deficits in accuracy of visual scanning, immediate and delayed visual memory, bimanual tactile discrimination, perceptual abstraction and rule learning skills, right ear auditory information processing and dominant hand motor speed. These results suggested that the disease may affect visual information processing, memory, sharing of information between the two hemispheres, rule learning, auditory information processing and motor skills. It was concluded that many survivors are left with undiagnosed neurocognitive deficits that are wrongly assumed to have fully resolved (Dugbartey 1995). A drawback of this study was the limited sample size for the CM group $(n=20)$.

A larger study conducted in Kenya compared 87 children exposed to severe malaria with impaired consciousness to age and gender matched healthy children on the Kilifi 
P. Bangirana et al. Cerebral malaria in African children

Assessment Battery (a modification of the Kaufmann Assessment Battery for Children) measuring information processing, language development and behaviour (Holding et al. 1999). Although there was no overall significant difference in information processing between the two groups, a significant difference in the 'impairment score' (this is the number of information processing subtests in which an impaired performance was recorded) was observed between the two groups. They found that $14 \%$ of the exposed children were cognitively impaired (had an impaired score in two or more subtests) compared with $4 \%$ of the unexposed children. The exposed children had significantly poorer performances in attention/visual search, syntax, articulation and in behaviour. This study with a wider inclusion criterion as opposed to strictly defined CM suggested that children with the deeper coma seen in CM may suffer significant cognitive deficits on recovery.

Deficits in cognitive test performance were also found in a sample of Senegalese children. Twenty-nine children with a history of CM were compared with age-matched children on tests of information processing and attention (Boivin 2002). The CM group had a significantly poorer performance on measures of attention, short-term memory and visual spatial processing than the healthy children. Further analysis showed that inattention in the CM group affected their scores in Sequential and Simultaneous Processing, implying that the disease effects on attention may impair performance in attention-dependent tasks (Boivin 2002). Lower parental literacy rates, lower parental occupational levels and fewer nutritional resources also affected performance in Sequential and Simultaneous Processing.

In investigating the long-term neurocognitive outcome of $\mathrm{CM}$ and other complications of malaria in Kenya, Carter et al. $(2005 \mathrm{a}, \mathrm{b})$ compared 152 children with a history of CM with 156 with a history of multiple seizures (MS) and 179 children unexposed to severe malaria on tests of cognition, motor, speech and language, hearing and vision. The CM and MS groups each had 24\% with impaired scores in at least one domain compared with $10 \%$ of the unexposed group. The CM group had 10\% compared with $7 \%$ of the MS who were impaired in two or more domains. Of the functions tested that fall with the cognitive skills bracket, speech and language had the highest impairment rate for both CM (12\%) and MS (9\%) groups. In these two groups, presence of active epilepsy (two or more seizures unrelated to fever with at least one in the last 12 months) significantly increased the likelihood of cognitive and behavioural problems. Deficits in speech and language functions after CM have also been reported elsewhere (Holding et al. 1999; Carter et al. 2003) suggesting that language deficits after CM in young children may persist if early interventions are not carried out.

However, one study evaluating the neuropsychological effects of CM in children using a retrospective matchedgroup design, failed to find significant evidence of neuropsychological deficits (Muntendam et al. 1996). In this study, the CM children were comparable or slightly superior on all five intellectual development tests. Muntendam et al. (1996) concluded from these findings that the long-term impact of CM on the development of children who recover without major neurological deficits is not as serious as had been feared. Muntendam's unlikely findings of superior CM neuropsychological performance compared with the healthy group could be understood in light of the possible confounding influence of differing child education, parental education, quality of home environment and immediate health history characteristics of the CM and comparison groups (e.g. intestinal parasite infection, incidence of anaemia and history of malnutrition) (Richter \& Grieve 1991; Boivin et al. 1993; Lozoff et al. 1995, 2004; Grantham-McGregor \& Ani 2001; Boivin 2002; Holding et al. 2004).

There are no large prospective community-based studies that have examined the burden and incidence of cognitive impairment after CM. Holding et al. (1999) had earlier found a $14 \%$ prevalence of cognitive impairment after CM while Carter et al. (2005a,b) found a prevalence of $12 \%$, suggesting that $12-14 \%$ of children with a history of CM may develop long-term cognitive impairments.

\section{Conclusion from the review of research on the cognitive effects of cerebral malaria in children}

Despite the use of different assessments in different settings, these studies show that CM in children may lead to long-term deficits in cognitive functions. Deficits in attention, memory and visual skills seem to be the commonest deficits (observed in three of the four studies) followed by speech and language (observed in two of the four studies). These similar deficits in different studies suggest that $\mathrm{CM}$ affects brain regions where these functions are controlled. All studies were performed retrospectively and therefore highlight the long-term cognitive outcomes of CM. There are no published studies that document the short-term cognitive outcomes of CM.

\section{Justification for cognitive rehabilitation in cerebral malaria}

The number of children in sub-Saharan African left with cognitive deficits annually as a result of CM has not been clearly established. One other study that attempted to 
estimate the frequency of neurocognitive impairments at discharge after CM stated that between 1306 and 7812 child survivors in sub-Saharan Africa will develop impairment in at least one function each year (Mung'ala-Odera et al. 2004). Carter et al. (2005b) later estimated that 250000 children in sub-Saharan Africa will develop impairments as a result of severe malaria annually. These figures were based on the 1.1/1000 incidence for CM and 5.8/1000 for MS.

The estimates given by Mung'ala-Odera et al. (2004) seem to be much lower based on the following statistics: CM annually affects 575000 children below 5 years of age in sub-Saharan Africa, of whom 110000 die (Murphy \& Breman 2001), leaving some survivors with long-term cognitive deficits. If long-term cognitive impairment is observed in 12-14\% of CM survivors (Holding et al. 1999; Carter et al. 2005a,b), then 55 800-65 100 children in sub-Saharan African will develop long-term cognitive sequelae annually as a result of CM. We propose that the figure for cognitive impairment at discharge is even greater. First, the figures derived by Murphy and Breman (2001) did not include children above 5 years yet the $12-14 \%$ rates of cognitive impairment were derived from studies in children 6-9 years performed at least 20 months postdischarge. Second, children whose impairment may have resolved by the time these studies were performed are not accounted for. Third, some children having cognitive deficits may have died a few months after discharge as a result of severe neurological sequelae (Newton et al. 2000). Fourth, the $12 \%$ impairment rate was derived from Holding et al. (1999) where children with a coma score $>2$ as opposed to the $\leq 2$ required for CM diagnosis were included in the study. Inclusion of these children with 'less severe' malaria could have reduced the impairment rate as all the impaired children had a coma score $\leq 2$ with no impaired child having a score $>2$.

\section{Applicability of cognitive rehabilitation to cerebral malaria}

Disruptions in attention and memory functions are the commonly reported cognitive deficits after paediatric CM (Dugbartey 1995; Holding et al. 1999; Holding \& Snow 2001; Boivin 2002; Carter et al. 2005a,b) suggesting neuronal damage to regions associated with attention and memory functions. These deficits are also common in paediatric traumatic brain injury (TBI) (Anderson et al. 1999; Max et al. 2004; McCauley \& Levin 2004) for which successful interventions have been carried out (Van't Hooft et al. 2003). Although the pathophysiology of TBI and CM may be different, developing and implementing cognitive rehabilitation strategies for CM would greatly benefit from adapting the already proven TBI rehabilitation strategies.

The CM studies above provide four areas that may be targeted for intervention. First, the documented cognitive deficits in CM have been related to the disease's effect on the attention systems that are necessary for the performance of a wide variety of cognitive tasks (Boivin 2002). Interventions will therefore have to strengthen the attention systems through cognitive training exercises and develop compensatory skills for those severely impaired. These cognitive exercises have helped improve attention and memory in brain injured children (NIH 1998; Van't Hooft et al. 2003).

The second area of intervention is evident from the effects of parental literacy, occupational levels and nutritional resources in the home on cognition (Boivin 2002) as well as the potential effect of providing stimulation and educational opportunities on cognitive functioning after CM (Holding et al. 1999). This demonstrates the relationship between the quality of the home environment and cognitive functioning - hence the need for interventions that foster the provision of stimulation and learning opportunities in the home through enrichment of the home/ learning environment. Children who received interventions that enriched the home and learning environment show better cognitive functioning than those who did not (Klein 1991; Raine et al. 2001; Klein \& Rye 2004).

In addition to cognitive deficits, $10.9 \%$ of CM child survivors display neurological sequelae (Newton et al. 2000) highlighting the need for interventions to deal with neurological complications that may hinder participation in cognitive rehabilitation. Children receiving physical therapy and speech therapy show an improvement in motor and language skills, respectively (Goorhuis-Brouwer \& Knijff 2002; Blundell et al. 2003).

Lastly, associations between malnutrition and poor outcomes (death or recovery with neurological sequelae) in children with CM have been observed (Genton et al. 1997; Olumese et al. 1997). The Senegalese children in Boivin (2002) also had poor cognitive performances if they had fewer nutritional resources. Since enriching the child's nutritional status, eliminating intestinal parasites and treatment of iron deficiency has resulted in improved cognitive functioning (Boivin \& Giordani 1993; Boivin et al. 1996; Grantham-McGregor \& Ani 2001 and Stoltzfus et al. 2001), such efforts may supplement the effects of the cognitive rehabilitation programme for CM.

On the basis of the above principles, we propose that interventions comprised of cognitive rehabilitation therapy (CRT), environmental enrichment, physical therapy for neurological sequelae, speech therapy and nutritional enrichment may enhance cognitive functioning in African 
children discharged with CM. We present a review of the some of these interventions addressing their strengths and limitations.

\section{Cognitive rehabilitation therapy}

The two major forms of CRT are traditional rehabilitation that involves training cognitive strategies to alleviate deficits in attention, concentration, visual processing, language, memory, reasoning, problem-solving and executive functions and computer-assisted cognitive rehabilitation that utilizes computers to train attention, problem solving plus other skills in a game-like fashion (see Chen et al. 1997 for a review).

\section{Traditional cognitive rehabilitation therapy}

Traditional CRT strategies are compensatory in nature in that they help the patient circumvent a deficit caused by brain impairment (Dirette 2002). One of the compensatory interventions is the Developmental Metacognitive Approach described in Laatsch and Stress (2000)) that's based on the theory that basic cognitive abilities like attention should be the focus of rehabilitation before advanced skills like memory and problem solving are treated. Another intervention programme for children with executive disorders described by Marlowe (2000) involves teaching children to focus on their own thinking in the hope of enhancing their verbal skills that are useful in selfregulation and directing behaviour. Traditional CRT has shown effectiveness in improving neuropsychological functioning of patients with TBI (Cicerone et al. 2004; Laatsch \& Stress 2000). Simultaneous improvement in neuropsychological test performance and increase in relative cerebral blood flow in areas around the injury observed after traditional CRT (Laatsch et al. 1997, 1999) prove its efficacy in improving brain function.

\section{Computer-assisted cognitive rehabilitation therapy}

Computer assisted CRT is either task specific where the target is to improve functioning in a specific ability like memory or hierarchical where the aim is to improve overall cognitive functioning with simple cognitive tasks like attention being trained first and then more complex ones like problem solving following later (Chen et al. 1997; Gontkovsky et al. 2002). Attention Process Training (APT; Sohlberg \& Mateer 1987) and The Amsterdam Memory and Attention Training for Children (AMAT-c; Van't Hooft et al. 2003) are examples of task specific interventions that improve performance in trained tasks and neuropsychological measures of attention and memory
(Sohlberg \& Mateer 1987; Palmese \& Raskin 2000; Zillmer \& Spiers 2001; Van't Hooft et al. 2003). Cognitive functioning also improved in brain-injured patients who received hierarchical computerized interventions (Chen et al. 1997; Gontkovsky et al. 2002).

\section{Benefits of cognitive rehabilitation therapy programmes in children}

Computerized cognitive training programmes may be helpful to children who have suffered early brain insult, either from trauma or infectious disease. The benefit may be both in terms of cognitive rehabilitation from the effects of the disease, and from the developmental enhancement of brain processes from a more enriched cognitive/sensory environment. In a special working group assembled by the $\mathrm{NIH}$ in 1998 to evaluate the effectiveness of cognitive training exercises, the consensus statement was that:

"Cognitive exercises, including computer assisted strategies, have been used to improve neuropsychological processes, predominately attention, memory and executive skills." "Both randomized controlled studies and case reports have documented the success of these interventions." "Certain studies using global outcome measures also support the use of computer assisted exercises in cognitive rehabilitation" (NIH 1998).

However, these cognitive exercises have not been implemented in sub-Saharan African countries, probably because of lack of skilled professionals, failure to recognize the problem, lack of logistical and financial resources (Olness 2003). It is our expectation that this sort of computerized cognitive training intervention could be of benefit to children affected by CM who struggle with attention, memory, language and executive cognitive skills as a result of the neuropsychological effects of the disease. Without collaborative research and training between African scientists and colleagues from developed countries, these interventions may never be available for the African population.

\section{Limitations of cognitive rehabilitation therapy}

Developing countries, where most of these services are needed, lack qualified personnel to provide them (Olness 2003). The use of expensive computerized equipment may make computer assisted CRT available to only the urban communities in developing countries. Electricity supply is unreliable or non-existent in many rural areas. Computer literacy is questionable, which may limit the number of people who may assist in providing these services. Some of 
the studies using computer assisted CRT like Van't Hooft et al. (2003) and Sohlberg and Mateer (1987) were conducted with small sample sizes, making it difficult to generalize the results and their cross-cultural application. The AMAT-c has no provision for children below 6 years and takes a considerable amount of time, such that it may interfere with school activities. The use of compensatory strategies in traditional CRT depends on the patient's awareness of his/her problem (Dirette 2002) that may make these interventions difficult for young children. Since studies have not specifically localized sites of injury in CM, there is a need to do so, so that brain site specific interventions can be designed to treat and rehabilitate these cognitive impairments.

\section{Environmental enrichment}

Animal studies have provided evidence on how enriching the environment and providing stimulation can improve brain development and behaviour (Mohammed et al. 2002; Fernandez-Teruel et al. 2002). We present two possible interventions for $\mathrm{CM}$ in African children that target early childhood education and nutrition as well as the parent-child interaction.

\section{Early childhood education and nutrition enrichment}

In one of the first studies to experimentally manipulate the child's environment and examine the effects on brain functioning, an experimental group of children 3-5 years matched to a control group on psychophysiological measures, gender and ethnicity was entered into a 2 -year nursery school enrichment programme comprised of good nutrition, good education and regular physical exercise while the control group went through the traditional Mauritius kindergartens with untrained staff, poorer education, a higher pupil/teacher ratio and poor feeding arrangements (Raine et al. 2001). When both groups were tested 6-8 years later on skin conductance (SC) and electroencephalogram (EEG) measures of arousal and attention, the enriched group had increased SC and EEG measures reflecting enhanced information processing of neutral, speech like and aversive stimuli, faster maturation of the cortex and increase in cortical activity during rest and active conditions (Raine et al. 2001).

The effects of enrichment on cognition were also observed by Boivin et al. (1996) who enrolled Congolese children in an educational and nutritional enrichment programme. These children performed better than their counterparts from nearby villages on measures of verbal, visual, logical and basic school skills and on the global indicator of cognitive ability although the two groups did not differ significantly on motor or physical development.

\section{Parent-child interaction intervention}

Another environmental intervention targeting the childcaregiver interaction is the Mediational Intervention for Sensitising Caregivers (MISC) whose objective is to provide a suitable parent-child relationship that enhances the child's disposition for learning (Klein 1991; Klein \& Rye 2004). This programme focuses on sensitising caregivers to the child's needs by helping them become more aware of the potentially positive qualities of their interactions with their children and how to maximize these qualities to support their child's development, stimulate it's potential for interacting, learning and mastering the environment.

Evaluation 1 year later of Ethiopian children whose families had participated in MISC showed them to be less hostile, aggressive, anxious, hyperactive or distractible than children from families who received a basic health and nutrition intervention. There were more MISC children attending school and their performance was significantly better than the control group children (Klein \& Rye 2004). MISC rarely conflicts with ongoing educational programmes or traditional ways of child rearing and has thus been used in several countries (Klein \& Rye 2004). The cultural adaptability, ease of application and positive effects on child development of MISC makes it a potentially suitable rehabilitation programme for $\mathrm{CM}$ survivors.

\section{Limitations of environmental enrichment interventions}

Sub-Saharan Africa lacks skilled professionals to train personnel and implement such interventions (Olness 2003). Lack of rehabilitation services and knowledgeable personnel have also been pointed as some of the shortcomings in brain injury rehabilitation in developed countries (NIH 1998). It is difficult to create similar environmental conditions for all study subjects especially between follow-up sessions and this was cited as one of the shortcomings of the Mauritius study (Raine et al. 2001).

\section{Physical therapy for motor deficits}

Neurological deficits are present in $10.9 \%$ of the CM survivors (Newton et al. 2000) of which hemiplegia and speech disorders are the top two persisting neurological complications of CM in Africa (WHO 2000). Physical therapy improves motor functioning (Blundell et al. 2003) 
and can thus be used to resolve these deficits. Physical exercise in humans has been shown to sustain cerebral blood flow, enhance cognitive functioning, produce positive changes in mood while in animals it increases cell proliferation and neurogenesis (see Grealy \& Heffernan 2001 for a review). Physical therapy therefore would not only help in resolving the motor deficits after CM but also leads to physiological changes in the brain that may enhance cognitive functions and thus should not only be reserved for those with neurological deficits. However, most of the research looking at physical exercise in rehabilitation has been conducted with adults, making it difficult to generalize its effects to child populations. It is not known what intensity, duration and frequency of exercise is needed for brain-injured children (Grealy \& Heffernan 2001).

\section{Speech therapy}

The studies reviewed above show that speech and language disorders are a common sequelae of CM (Holding et al. 1999; WHO 2000; Carter et al. 2003, 2005a,b) highlighting the need for intervention. Speech therapy helps children with language impairment improve their language skills (Goorhuis-Brouwer \& Knijff 2002) and should be included in rehabilitation programmes for children with CM.

\section{Nutritional enrichment}

Poor nutritional status in children with CM has been associated with cognitive impairment, neurological deficits and death (Genton et al. 1997; Olumese et al. 1997; Boivin 2002). The potential benefits of nutritional enrichment on cognitive functioning in children have been demonstrated in studies that treated intestinal parasites (Boivin \& Giordani 1993; Boivin et al. 1993) and provided iron supplements (Boivin \& Giordani 1993; Grantham-McGregor \& Ani 2001). Early childhood education interventions that incorporated good nutrition have shown immediate and long-term benefits in cognitive development (Boivin et al. 1996; Raine et al. 2001). Although the association between treatment of intestinal parasites or iron supplementation and cognitive performance or development in children is still controversial (Dickson et al. 2000; Grantham-McGregor \& Ani 2001), the observed relationship between intestinal parasites or low iron and poor cognitive performance warrants the use of nutritional enrichment in rehabilitation.

Not all children with cognitive impairment will require all the above interventions, the choice will depend on what deficit the child has. CRT would be the intervention of choice if the child's deficit can be identified. For younger children, who cannot perform these cognitive exercises or achieve the compensatory techniques, environmental enrichment is recommended. Speech and physical therapy are required for those with language and motor deficits (though physical exercises for those without neurological deficits can be helpful as well). Nutritional enrichment can supplement the efforts of the above interventions and should be recommended for all children.

The choice of intervention may also depend on the time the child is seen. Children seen immediately after discharge may first require speech and physical therapy to deal with language and motor deficits that may hinder participation in CRT. At 12 or more months after discharge, speech and physical therapy may not always precede CRT as most neurological deficits should have resolved by then.

\section{Feasibility of proposed interventions}

In order to make the above interventions feasible in an African setting, the above limitations have to be addressed. Clearly the most important limitation to their provision in sub-Saharan Africa is the lack of skilled professionals. Through collaborative training and research between scientists in the developed world and those in sub-Saharan Africa, provision of these interventions in African communities can become a reality.

With skilled professionals available, efforts should then be made to have these services available to rural communities who may not have access to the urban hospitals providing these services. By employing the same methods used in community-based rehabilitation (CBR), these proposed interventions can become available to the rural communities. In CBR, all levels of society (national, intermediate and community) are involved in providing rehabilitation services (see Nordholm \& Lundgren-Lindquist 1999 for an overview).

At the national level, the government plans, implements, coordinates and evaluates the intervention in cooperation with the communities, intermediate level and organizations of disabled people. At the intermediate level, government provides the professional support personnel who train and supervise the community workers. At the community level, community personnel mobilize local resources and provide support to families carrying out the interventions from the homes. Community personnel also carry out education, training and ensure that the disabled are not deprived of their human 
rights (see Nordholm \& Lundgren-Lindquist 1999 for an overview).

\section{Programme evaluation}

There is no documentation of cognitive rehabilitation for $\mathrm{CM}$ - hence the need for evaluation across a broad range of outcome measures. Using improvements in neuropsychological test performance, neurophysiological processes, education, achievement tests and activities of daily living as the outcome measures will enhance the effectiveness of the interventions ensuring a holistic approach to child rehabilitation. These interventions are best implemented initially as clinical trials where the effect of the intervention on the outcome measure in one group of patients is compared with a second group that does not receive the intervention using pre- and post-intervention assessments. These evaluations can be performed at 3- or 6-month intervals throughout the duration of the intervention and even after. Long-term follow-ups for these children are recommended because episodes of seizures after discharge common in CM may worsen cognitive outcomes (Carter et al. 2005b). However there are few culturally appropriate tests that can accurately measure cognitive deficits after CM. Such tests are needed if we are to assess the effects of interventions in patients.

\section{Conclusion}

The annual burden of CM's effects on the cognitive functioning of children calls for rehabilitation services. CRT and modification of the child's environment to improve child-caregiver interaction may lead to improved cognitive functioning in CM survivors. These efforts can be supplemented with physical and speech therapy to overcome motor and speech difficulties and improve brain function as well nutritional interventions to supplement the gains from cognitive rehabilitation. Practical and more easily implemented measures like the MISC and nutritional counselling and supplementation may be most feasible in rural or resource poor areas, but computer-based CRT is likely to be feasible and effective in some urban areas of Africa. Periodic evaluation of the intervention across a wide range of outcome measures to ensure a holistic intervention is recommended.

\section{Acknowledgements}

We would like to thank Dr Justus Byarugaba, Senior Consultant Paediatician, Mulago Hospital and Dr Zongqi Xia, Case Western Reserve University for reviewing earlier drafts of this manuscript.

\section{References}

Anderson VA, Catroppa C, Morse SA \& Haritou F (1999) Functional memory skills following traumatic brain injury in young children. Pediatric Rehabilitation 3, 159-166.

Boivin MJ (2002) Effects of early cerebral malaria on the cognitive ability of Senegalese children. Journal of Developmental and Behavioral Pediatrics 23, 353-364.

Boivin MJ \& Giordani B (1993) Improvements in cognitive performance for school children in Zaire, Africa, following an iron supplement and treatment for intestinal parasites. Journal of Pediatric Psychology 18, 249-264.

Boivin MJ, Giordani B, Ndanga K et al. (1993) Effects of treatment for intestinal parasites and malaria on the cognitive abilities of school children in Zaire, Africa. Health Psychology 12, 220-226.

Boivin MJ, Giordani B, Ndanga K, Maky MM, Manzeki KM \& Ngunu N (1996) Economic advantage and the cognitive ability of rural children in Zaire, Africa. Journal of Psychology 130, 95-107.

Blundell SW, Shepherd RB, Dean CM \& Adams RD (2003) Functional strength training in cerebral palsy: a pilot study of a group circuit training class for children aged 4-8 years. Clinical Rehabilitation 17, 48-57.

Carter JA, Murira GM, Ross AJ, Mung'ala-Odera V \& Newton CRJC (2003) Speech and language sequelae of severe malaria in Kenyan children. Brain Injury 17, 217-224.

Carter JA, Mung'ala-Odera V, Neville BGR et al. (2005a) Persistent neurocognitive impairments associated with severe falciparum malaria in Kenyan children. Journal of Neurology Neurosurgery and Psychiatry 76, 476-481.

Carter JA, Ross AJ, Neville BGR et al. (2005b) Developmental impairments following severe falciparum malaria in children. Tropical Medicine and International Health 10, 3-10.

Chen SHA, Thomas JD, Glueckauf RL \& Bracy OL (1997) The effectiveness of computer-assisted cognitive rehabilitation for persons with traumatic brain injury. Brain Injury 11, 197-209.

Cicerone KD, Mott T, Azulay J \& Friel JC (2004) Community integration and satisfaction with functioning after intensive cognitive rehabilitation for traumatic brain injury. Archives of Physical Medicine and Rehabilitation 85, 943-950.

Dickson R, Awasthi S, Williamson P, Demellweek C \& Garner P (2000) Effects of treatment for intestinal helminth infection on growth and cognitive performance in children: systematic review of randomised trials. British Journal of Medicine 320, 1697-1701.

Dirette D (2002) The development of awareness and the use of compensatory strategies for cognitive deficits. Brain Injury 16 , 861-871.

Dugbartey AT (1995) The neuropsychology of cerebral malaria. Doctoral dissertation, University of Victoria, Canada.

Dugbartey AT, Spellacy FJ \& Dugbtery MT (1998) Somatosensory discrimination deficits following pediatric cerebral malaria. American Journal of Tropical Medicine and Hygiene 59, 393-396.

Fernandez-Teruel A, Gimenez-Llort L, Escorihuela RM et al. (2002) Early-life handling stimulation and environmental 
P. Bangirana et al. Cerebral malaria in African children

enrichment: are some of their effects mediated by similar neural mechanisms? Pharmacology, Biochemistry and Behavior 73, 233-245.

Genton B, Al-Yaman F, Alpers MP \& Mokela D (1997) Indicators of fatal outcome in paediatric cerebral malaria: a study of 134 comatose Papua New Guinean children. International Journal of Epidemiology 26, 670-676.

Goorhuis-Brouwer SM \& Knijff WA (2002) Efficacy of speech therapy in children with language disorders: specific language impairment compared with language impairment in comorbidity with cognitive delay. International Journal of Pediatric Otorbinolaryngology 63, 129-136.

Gontkovsky ST, McDonald NB, Clark PG \& Ruwe WD (2002) Current directions in computer-assisted cognitive rehabilitation. NeuroRehabilitation 17, 195-199.

Grantham-McGregor S \& Ani C (2001) A Review of studies on the effect of iron deficiency on cognitive development in children. Journal of Nutrition 131, 649S-668S.

Grealy MA \& Heffernan D (2001) The rehabilitation of brain injured children: the case for including physical exercise and virtual reality. Pediatric Rehabilitation 4, 41-49.

Holding PA \& Snow RW (2001) Impact of Plasmodium Falciparum malaria on performance and learning: review of the evidence. American Journal of Tropical Medicine and Hygiene 64, 68-75.

Holding PA, Stevenson J, Peshu N \& Marsh K (1999) Cognitive sequelae of severe malaria with impaired consciousness. Transactions of the Royal Society of Tropical Medicine and Hygiene 93, 529-534.

Holding PA, Taylor HG, Kazungu SD et al. (2004) Assessing cognitive outcomes in a rural African population: development of a neuropsychological battery in Kilifi District, Kenya. Journal of the International Neuropsychological Society 10, 246-260.

Klein PS (1991) Improving the quality of parental interaction with very low birth weight children: a longitudinal study using a mediated experience model. Infant Mental Health Journal 12, 321-337.

Klein PS \& Rye H (2004) Interaction - oriented early intervention in Ethiopia: the MISC approach. Infants and Young Children 17, 340-354.

Laatsch L \& Stress M (2000) Neuropsychological change following individualized cognitive rehabilitation therapy.

NeuroRehabilitation 15, 189-197.

Laatsch L, Jobe T, Sychra J, Lin Q \& Blend M (1997) Impact of cognitive rehabilitation therapy on neuropsychological impairments as measured by brain perfusion SPECT: a longitudinal study. Brain Injury 11, 851-863.

Laatsch L, Pavel D, Job T, Lin Q \& Quintana JC (1999) Incorporation of SPECT imaging in a longitudinal cognitive rehabilitation therapy programme. Brain Injury 13, 555-570.

Lozoff B, Park AM, Radan AE \& Wolf AW (1995) Using the HOME inventory with infants in Costa Rica. International Journal of Behavioral Development 18, 277-295.

Lozoff B, De Andraca I, Castillo M, Smith JB, Walter T \& Pino P (2004) Behavioral and developmental effects of preventing iron-deficiency anemia in healthy full-term infants. Pediatrics 112, 846-854. Erratum in: Pediatrics 113, 1853.

Marlowe WB (2000) An intervention for children with disorders of executive functions. Developmental Neuropsychology 18, $445-454$.

Max JE, Lansing AE, Koele SL et al. (2004) Attention deficit hyperactivity disorder in children and adolescents following traumatic brain injury. Developmental Neuropsychology 25, 159-177.

McCauley SR \& Levin HS (2004) Prospective memory in pediatric traumatic brain injury: a preliminary study. Developmental Neuropsychology 25, 5-20.

Mohammed AH, Zhu SW, Darmopil S et al. (2002) Environmental enrichment and the brain. Progress in Brain Research 138, 109-133.

Mung'ala-Odera V, Snow RW \& Newton CJRC (2004) The burden of the neurocognitive impairment associated with Plasmodium falciparum malaria in sub-Saharan Africa. American Journal of Tropical Medicine and Hygiene 71 (Suppl. 2), 64-70.

Muntendam AH, Shabbar J, Bleichrodt N \& van Hensbroek MB (1996) Absence of neuropsychological sequelae following cerebral malaria in Gambian children. Transactions of the Royal Society of Tropical Medicine and Hygiene 90, 391-394.

Murphy SC \& Breman JG (2001) Gaps in the childhood malaria burden in Africa: cerebral malaria, neurologic sequelae, anemia, respiratory distress, hypoglycemia and complications of pregnancy. American Journal of Tropical Medicine and Hygiene 64 (Suppl. 1, 2), 57-67.

Newton CRJC, Hien TT \& White N (2000) Cerebral malaria. Journal of Neurology Neurosurgery and Psychiatry 69, 433-441.

NIH (1998) Rehabilitation of persons with traumatic brain injury. NIH Consensus Statement 16, 1-41.

Nordholm LA \& Lundgren-Lindquist B (1999) Community-based rehabilitation in Moshupa village, Botswana. Disability and Rehabilitation 21, 515-521.

Olness K (2003) Effects on brain development leading to cognitive impairment: a worldwide epidemic. Journal of Developmental and Behavioral Pediatrics 24, 120-130.

Olumese PE, Sodeinde O, Ademowo OG \& Walker O (1997) Protein energy malnutrition and cerebral malaria in Nigerian children. Journal of Tropical Pediatrics 43, 217-219.

Palmese C \& Raskin SA (2000) The rehabilitation of attention in individuals with mild traumatic brain injury, using the APT-II programme. Brain Injury 14, 535-548.

Raine A, Venables PH, Dalais C, Mellingen K, Reynolds C \& Mednick SA (2001) Early educational and health enrichment at age 3-5 years is associated with increased autonomic and central nervous system arousal and orienting at age 11 years: evidence from the Mauritius child health project. Psychophysiology 38, 254-266.

Richter LM \& Grieve KW (1991) Home environment and cognitive development of black infants in impoverished South African families. Infant Mental Health Journal 12, 89-102. 


\section{P. Bangirana et al. Cerebral malaria in African children}

Snow RW, Guerra CA, Noor AM, Myint HY \& Hay SI (2005) The global distribution of clinical episodes of Plasmodium falciparum malaria. Nature 434,

214-217.

Sohlberg MM \& Mateer CA (1987) Effectiveness of an attention training program. Journal of Clinical and Experimental Neuropsychology 9, 117-130.

Stoltzfus RJ, Kvalsvig JD, Chwaya HM et al. (2001) Effects of iron supplementation and anthelmintic treatment on motor and language development of preschool children in Zanzibar: double blind, placebo controlled study. British Medical Journal 323, 1389-1396.

Van't Hooft I, Andersson K, Sejersen T, Bartfai A \& von Wendt L (2003) Attention and memory training in children with acquired brain injuries. Acta Paediatrica 92, 935-940.

World Health Organization (2000) Severe falciparum malaria. Transactions of the Royal Society of Tropical Medicine and Hygiene 94 (Suppl. 1), S1-90.

Zillmer EA \& Spiers MV (2001) Principles of Neuropsychology. Wadsworth, CA.

Corresponding Author Paul Bangirana, Department of Mental Health and Community Psychology, Makerere University Institute of Psychology, PO Box 7062, Kampala, Uganda. Tel: +256-772-673831; E-mail: pbangirana@yahoo.com

Rééducation des troubles cognitifs séquellaires d'un neuropaludisme pour des enfants africains: Stratégies et limitations

Des troubles cognitifs se manifestent à court ou long terme chez de nombreux enfants survivant à un épisode de neuropaludisme. Certains facteurs de risque ont été identifiés, mais aucun effort n'a été fait pour essayer d'améliorer les conditions de vie difficiles de ceux développant des troubles cognitifs. Cet article discute le poids des troubles cognitifs provoqués par le neuropaludisme et suggère quelques stratégies de rééducation basées sur des études de rééducation cognitive lors de dommages cérébraux. Des solutions de rééducation cognitive telles que des exercices cognitifs, l'enrichissement environnemental, la supplémentation alimentaire, la thérapie physique ou la thérapie par la parole sont soulignées. Les limitations de la mise en place de telles interventions sont discutées en tennant compte des capacités limitées en terme de ressources humaines et d'infrastructures des pays en voie de développement où le paludisme sévit de façon endémique.

mots clés neuropaludisme, troubles cognitifs, Afrique, enfants, rééducation

Rehabilitación del deterioro cognitivo después de malaria cerebral en niños africanos: estrategias y limitaciones

La malaria cerebral da como resultado un deterioro cognitivo de corto a largo plazo en muchos de los niños sobrevivientes. A pesar de que algunos de los factores de riesgo de deterioro han sido identificados, no se ha intentado resolver las difíciles condiciones de aquellos que han desarrollado deterioros cognitivos. Este trabajo discute el peso del deterioro cognitivo causado por malaria cerebral y sugiere algunas estrategias de rehabilitación, basadas en estudios sobre daños cerebrales y rehabilitación cognitiva. Se ponen de relieve potenciales soluciones de rehabilitación cognitiva como ejercicios cognitivos, enriquecimiento ambiental, suplementación nutricional, y terapias físicas y del lenguaje. Se discute las limitaciones para la implementación de estas soluciones e intervenciones, a la luz de las limitaciones en infraestructuras y recursos humanos de los países en desarrollo donde la malaria es endémica.

palabras clave Malaria cerebral, deterioro cognitivo, África, niños, rehabilitación 